\author{
И. А. Шаронов \\ Российский государственный гуманитарный университет \\ (Россия, Москва) \\ Igor_sharonov@mail.ru
}

\title{
ВВОДНЫЕ СЛОВА КАК МАРКЕРЫ И МОДИФИКАТОРЫ РЕЧЕВЫХ АКТОВ: БЫТОВЫЕ ПРИЗНАНИЯ
}

Статья посвящена прагматическому анализу информативных высказываний, маркируемых вводными словами и оборотами со значением признания в чем-л. На основе материала, собранного в НКРЯ, анализируется употребление двенадцати частотно используемых вводных слов и оборотов. Эти единицы включают лексику, связанную с покаянием: сознаваться, каяться, признаваться; с искренностью: не скрывать, откровенно, честно, правда, совесть, грех; с необходимостью: надо, нужно, необходимо, следует, должен. Речевые акты признания выходят за рамки смыслов, составляющих значение речевого глагола признаться и используются шире своего первоначального предназначения. Выявляются три типовые ситуации с подвидами для актов признания: 1) Сообщения о своих действиях (личное участие говорящего, факт в прошлом, негативная оценка). 2) Сообщения о действиях кого-л. (неличное участие говорящего, факт в прошлом и настоящем, негативная / позитивная оценка). 3 ) Оценочные суждения говорящего (неличное участие говорящего, мнение, негативная / позитивная оценка). Определяются нечеткие границы использования вводных единиц для той или иной типовой ситуации. На основе сопоставления с теми же высказываниями без вводных определяются этические установки, которые преодолеваются с помощью акта признания, и, возможно, национальные особенности речевого этикета.

Ключевые слова: вводные слова, прагматика, субъективная модальность, речевые акты, речевой жанр признания.

Семантика вводных слов и оборотов рассматривается в современной лингвистике в связи с их метатекстовыми и субъективно-модальными функциями, см. [Апресян 1995, Баранов, Кобозева 1984, Виноградов 1959, Падучева 2011, Шаронов 2017]. К последним относятся выражение отношения говорящего лица к содержанию своего сообщения, маркирование и модификация речевого акта (далее РА). 
Признания относятся к констативам, актам передачи информации, однако имеют свою специфику. Сообщение говорящего лица: Честно говоря, это сделал я в косвенной речи трансформируется в высказывание: Х признался, что это сделал он. Другими словами, произнеся Честно говоря..., говорящий передает сигнал собеседнику: 'Через данное высказывание я сообщу тебе информацию, которая должна быть оценена тобой как мое признание в чем-либо’.

Толкование речевого глагола признаться наряду с другими глаголами речи предложено в работах А. Вежбицкой и М. Я. Гловинской. А. Вежбицкая описывает акт признания как вынужденное, неохотное сообщение:

'Говорящему трудно совершать данное речевое действие, и он совершает его как бы против воли' [Вежбицкая 1984: 99-109].

Близким образом А. Вежбицкая толкует оборот по правде говоря, вводя дополнительный компонент 'истинность сообщаемого', который входит в пресуппозицию речевого акта (далее РА) признания:

' Я не хочу не сказать того, что является истиной. Я полагаю, что ты понимаешь, что я бы предпочел этого не говорить' [Вежбицкая 1968: 18].

М. Я. Гловинская усложняет толкование, выделяя у русского глагола признаться два значения (условно бытовое и юридическое) и добавляя в оба значения связь говорящего с описываемой ситуацией:

1. «Х признается $Y-y$, что $P$ a:

(1) $\mathrm{X}$ - субъект ситуации P или имеет к ней отношение;

(2) Раньше X не хотел говорить, что Р, потому что обычно людям трудно говорить такие вещи, как $\mathrm{P}$;

(3) X говорит Y-y, что P;

(4) $\mathrm{X}$ говорит это, потому что по внутренним или внешним причинам хочет сказать Ү-у, что Р.

2. Х признается, что $P$ (юрид.) =

(1) $\mathrm{X}$ совершил плохой поступок $\mathrm{P}$ или обладает нежелательным свойством $\mathrm{P}$;

(2) X говорит, что P;

(3) X говорит это потому, что внешние или внутренние обстоятельства заставляют его сказать правду;

(4) $\mathrm{X}$ знает, что его слова могут повлечь за собой изменения в его социальном статусе» (с.170) [Гловинская 1993: 170].

В первом значении связь говорящего с описываемой ситуацией выражена размыто: Говорящий является субъектом ситуации Р или имеет к ней какое-либо отношение, а во втором, «юридическом» - более определенно: говорящий совершил плохой поступок или обладает «нежелательным свойством». Кроме того, в «юридическом» значении акцентируется внимание на последствии для говорящего акта признания: сообщаемое актуально и может 'повлечь за собой изменения в его социальном статусе’ (там же, с. 170). Аналогичный компонент в первом значении не представлен, из чего можно сделать вывод, что описываемые в таких признаниях прегрешения слабы для «изменений в социальном статусе», то есть для осуждения, наказания, или потеряли со временем свою силу. 
«Юридическое» значение более соответствует прототипическим признаниям признательным показаниям на следствии, христианской исповеди, покаянию. «Неюридическое» значение охватывает бытовые ситуации - распространенный в нашей культуре разговор “по душам”, доверительные беседы с близким другом [см. об этом в Шаронов 2012].

В бытовой речи компонент «вынужденность» обретает форму откровенности, сообщения собеседнику негативной, отрицательно оцениваемой информации, каким-то образом связанной с говорящим лицом. При этом предполагается, что изменение отношения собеседника к говорящему должны произойти скорее в лучшую, чем в худшую сторону. Как это возможно? С одной стороны, негативно оцениваемое событие, о котором говорящий, как будет далее видно, актом своего признания сожалеет или как бы сожалеет, не снижает его «моральный облик» в глазах адресата ввиду слабости, либо потери актуальности сообщаемого. С другой стороны, такого рода признания - свидетельство доверия к собеседнику, введение его в мир «своих», что повышает статус адресата и предполагает его признательность за доверие. Переход на более доверительный уровень может быть стимулирован и собеседником. Стратегии побуждения к такому переходу рассмотрены в работе [Верещагин, Ратмайр, Ройтер 1992], однако возможен и мотив «из песни слова не выкинешь», когда для полноценного рассказа такая информация оказывается необходимой.

«Юридические» признания часто не отличаются формально от прочих сообщений говорящего о себе, в качестве РА признания они интерпретируются на основе содержания. Специальным маркером «юридических РА признания» являются перформативы.

Сознавайтесь, и всё! Говорите: “Да, признаюсь, что я выступал на собрании потому, что хотел выгородить своих собутыльников (Ю.О. Домбровский. Факультет ненужных вещей).

За что вы его так? А за что вам надо? - спросил Ученик. Нас бы устроило, если бы вы из зависти, говорит ему Архивист. Это меня не украшает, сказал Ученик, но что делать, и заплакал. Была зависть, была. Признаюсь! А знаете, что было после того, как Ученик поплакал? Утёр он слёзы и сообщает: не буду каяться! Зачем мне каяться? (Д. Гранин. Зубр).

Прости меня, пожалуйста! Виновата, виновата, каюсь! (А. Белянин. Свирепый ландграф).

В отличие от вводных, перформативы как самостоятельные высказывания имеют фразовое ударение и отделяются от констативного высказывания паузой.

Бытовые речевые акты признания маркируются в речи вводными словами и оборотами (далее - вводными), интонационно связанными с содержательной частью высказывания. В однословных и неоднословных вводных используется лексика нескольких синонимических групп, связанных:

- с покаянием: сознаваться, каяться, признаваться;

- с искренностью: не скрывать, откровенно, честно, правда, совесть, грех;

- с необходимостью: надо, нужно, необходимо, следует, должен. 
Некоторые единицы представлены несколькими грамматическими вариантами: признаюсь, признаться; говорить - сказать; правду - по правде. В оборотах частотен прямой и инвертированный порядок компонентов: говоря откровенно / откровенно говоря; по совести сказать / сказать по совести; по чести сказать / сказать по чести.

Разумеется, здесь представлены не все единицы, маркирующие сообщение как РА признания; составить исчерпывающий список вводных едва ли возможно. Для исследования были выбраны 16 частотно представленных в Национальном корпусе русского языка (НКРЯ) единиц. Ниже представлена статистика количества примеров употребления вводных признания по убывающей на январь 2018 г.:

$\begin{array}{lr}\text { Честно говоря: } & 2116 \\ \text { (Честно) признаюсь: } & 1785 \\ \text { По правде говоря / сказать } & 1220 \\ \text { Если честно: } & 898 \\ \text { Не скрою: } & 808 \\ \text { Откровенно говоря: } & 732 \\ \text { Если честно } & 462 \\ \text { Каюсь: } & 297 \\ \text { Грешным делом: } & 279 \\ \text { Стыдно признаться: } & 167 \\ \text { Стыдно сказать: } & 161 \\ \text { (Надо) признаться } & 156 \\ \text { Честно признаться: } & 125 \\ \text { Чего греха таить: } & 124 \\ \text { По совести сказать: } & 100 \\ \text { Положа руку на сердце } & \text { около } 100\end{array}$

Мы исходим из того, что первые четыре единицы способны быть использованы в любой типовой ситуации признания. Поэтому были проанализированы контексты употребления остальных единиц 12 единиц. В задачу исследования входило:

- обнаружить причину перевода сообщения в форму признания,

- выявить косвенные акты, «маскирующиеся» под РА признания,

- попытаться выявить предпочтения и ограничения в выборе вводного в той или иной типовой ситуации РА признания.

Классификация обобщенных ситуаций использования бытовых признаний строится, во-первых, на противопоставлении факта и мнения (оценки), в пропозиции высказывания; во-вторых, на противопоставлении личного / неличного участия говорящего, в-третьих, на противопоставлении отрицательной / положительной оценки факта.

На основе указанных признаков все РА признания делятся на три типовые ситуации:

1) Сообщения о своих действиях (личное участие говорящего, факт в прошлом, негативная оценка). 
2) Сообщения о действиях кого-л. (неличное участие говорящего, факт в прошлом и настоящем, негативная / позитивная оценка).

3) Оценочные суждения говорящего (неличное участие говорящего, мнение, негативная / позитивная оценка).

Ближе всего к «прототипическим» актам признания подходят примеры относящиеся к первой типовой ситуации. Высказывания, относящиеся ко второй и третьей типовой ситуации представляют набор косвенных речевых актов. В светской и повседневной беседе представление своего сообщения как признания, то есть выражение косвенного сожаления о том, что приходится говорить об этом, часто бывает более убедительным. Кроме того, использование маски признания позволяет избежать нарушения принципа Полианны, который предполагает предпочтение собеседником в разговоре приятных для него тем неприятным, поскольку нивелирует этически и этикетно неоправданные стратегии речевого поведения (Leech 1983: 156). Принцип Полианны страдает известной неопределенностью, поскольку культуры могут различаться тем, что в каждой из них считается принятым, допустимым или недопустимым. Представляется, что сопоставление высказываний с вводным и без него может позволить выявить этические и этикетные эталоны, отступление от которых подталкивает к перестройке обычного сообщения в признание.

Рассмотрим последовательно обобщенные ситуации бытовых признаний в их разновидностях и используемые вводные слова и обороты.

1. Сообщения о своих действиях (личное участие говорящего, факт в прошлом, негативная оценка).

Действия здесь понимаются несколько расширительно, включают как физические, так и ментально-эмоциональные акты говорящего лица в прошлом. Они делятся на: 1.1. Проступки говорящего в прошлом (совершение проступков и несовершение должного, правильного). 1.2. «Неэталонные» эмоциональные мотивы и реакции. 1.3. Ошибочные мнения о ком-/чем-л. и нереализованные в прошлом планы, намерения.

1.1. Проступки говорящего в прошлом (совершение проступков и несовершение должного, правильного). Для этой типовой ситуации в корпусе не встретились примеры с вводными признаться, надо / честно / стыдно признаться, положа руку на сердие, чего греха таить.

Каюсь, мы нередко потешались над ним; посылали в этот «журнал» разные письма под самыми прозрачными псевдонимами, чуть ли не героев Достоевского или Лермонтова; невинный Сквориов не замечал и с гордостью письма печатал. (3. Гиппиус. Задумчивый странник).

Не скрою, я покривил душой перед Терещенко. (А. Рыбаков. Тяжелый песок).

Но «Кориолана» я раньше, стыдно сказать, не читал, ибо забыть «Кориолана» немыслимо. (А. Эфрос. Профессия: режиссер). 
После показа дама-жена что-то долго, тонко и очень интеллигентно говорила, но, по совести сказать, мы в одно ухо слушали, в другое выпускали. (В. Розов. Удивление перед жизнью).

Сопоставление сообщений с вводным признания и без него, ср.:

Каюсь, мы нередко потешались над ним VS Mbl нередко потешались над ним.

диагностирует наличие в высказывании с вводным компонента 'сожаление о своих действиях', так сказать, легкого самоосуждения с целью устранить негативную реакцию слушающего и приблизить его доверительностью. Компонент 'сожаление' как облегченная форма раскаяния не полностью совпадает с выделяемым в толкованиях глагола признаться компонентом 'вынужденность', сближаясь в этом к речевому жанру покаяния и отдаляясь от жанра признательных показаний на следствии.

1.2. «Неэталонные» эмоциональные мотивы и реакции. Примеры для такой типовой ситуации представлены в корпусе довольно богато и разнообразно.

Надо признаться, я испьтала облегчение, когда после сезона 1983 года из спорта ушли Наташа с Ростиком и Лена Гаранина с Игорем Завозинылм. (Н. Бестемьянова. Пара, в которой трое).

Каюсь, мне не достало мужества рассказать ииронинцам правду о Книге Смысла, особенно после моего визита в диспетчерскую такси. (М. Елизаров. Библиотекарь).

И мыться в эти дни не мылся - честно признаться, лень было. (Р. Сенчин. Квартирантка с двумя детьми).

Обсчитала меня рублей на шесть. Откровенно говоря, я немного растерялся. Не денег, естественно, жаль - за человека обидно (С. Довлатов. Наши).

Но тут уж я, чего греха таить, ужасно обрадовалась: все сделалось так, как мне хотелось, а я вроде и ни при чем. (В. Белоусова. По субботам не стреляю.)

Прошлым летом мы с женой как-то сидели, ужинали, светло ещуе было, и вдруг мимо окна пролетел мужчина. Жена закричала по-звериному, а во мне, стыдно сказать, заработал какой-то арифмометр, который с неправдоподобной скоростью вычислил время полета и выключился. (А. Щербаков. Пах антилопы).

Самонаблюдение позволяет говорящему делать обобщения:

По правде говоря, я человек очень азартный. (Н. Склярова. Если бы у медведя было ружье // «Вечерняя Москва», 2002.02.07) - Подождите, Владимир Александрович, справлюсь ли я? По совести сказать, опьта у меня нет никакого! (Л. Гумилевский. Судьба и жизнь).

Сопоставление сообщений с вводным признания и без него, ср.:

честно признаться, лень было VS лень было. 
Надо признаться, я испьтала облегчение, VS Я испьтала облегчение,

Откровенно говоря, я немного растерялся VS Я немного растерялся.

диагностирует наличие в высказывании с вводным компонента 'сожаление об отступлениях от эталона в эмоциональном поведении, характере'. Эталон, видимо, заключается в том, что человек должен в любой ситуации проявлять волю, рассудительность, хладнокровие, великодушие и прочие добродетели. Цель таких признаний та же - устранить негативную реакцию слушающего и приблизить его доверительностью.

1.3. Ошибки в представлении о ком-/чем-л. и нереализованные в прошлом планы, намерения. Наиболее частотно представлена такая ситуация в корпусе примерами в вводными грешным делом и по правде говоря.

1.3.1. Ошибки в представлении о ком-/чем-л.

Зная, что он киевлянин, я, признаюсь, грешным делом подумал, уж не был ли он при немцах полицаем <...> Но сведущие люди сказали мне, что Турганов при немцах в Киеве не был. (В. Войнович. Иванькиада, или рассказ о вселении писателя Войновича в новую квартиру).

- А я сразу определил, только посмотрел: “Вот это настоящие ребята, прожжённые фронтовики”. - А у меня, по правде говоря, было сомнение насчёт Баха, - сказал Герне (В. Гроссман. Жизнь и судьба).

\subsection{2. Нереализованные в прошлом планы, намерения, желания.}

И я, грешным делом, подумал, не здесь ли где золото, драгоценности? Даже покопал землю рукой под балкой, - пусто (И.П. Максимов. Дворец Эстергази (Из фронтового дневника).

Не огорчил даже тот очевидный факт, что из города его вывел не ангел о чем, по правде говоря, мечталось (Е. Водолазкин. Лавр).

Сопоставление сообщений с вводным признания и без него подводит к мысли об эталонах доброжелательства и прозорливости, к которым, видимо, также должен стремиться человек.

1.4. Бахвальство и жеманство под маской признания.

- “Нью-йоркер” - самый престижный журнал в Америке. Они заплатят вам несколько тысяч. - Ого! Откровенно говоря, я даже не слишком удивился. Наверное, потому, что слишком долго всего этого ждал. (С. Довлатов. Переводные картинки).

Не скрою, мне было приятно это напоминание о моей свердловской жизни. (И. К. Архипова. Музыка жизни).

Сопоставление сообщений с вводным признания и без него, ср.: 
Откровенно говоря, я даже не слишком удивился VS Я даже не слишком удивился.

Не скрою, мне было приятно VS Мне было приятно

диагностирует наличие в высказывании без вводного определенное бахвальство и жеманство, которые нарушают этикетную максиму скромности [Leech 1986]. Чтобы избежать это нарушение, такого рода сообщения и «рядятся» в акты признания. Использование форм признания в качестве такого косвенного РА достаточно резко ограничивает использование вводных. Для данных ситуаций вряд ли уместно использование единиц с компонентами сознаваться, надо, нужно, необходимо, следует, должен. Примеров с этими компонентами в корпусе обнаружено не было.

2) Сообщения о действиях кого-л. (неличное участие говорящего, факт в прошлом и настоящем, негативная / позитивная оценка). Наиболее часто используемые вводные: стыдно сказать, чего греха таить, не скрою.

С 13 октября начали эвакуировать из Москвы дипломатов и центральные учреждения, и тут же стали бежать и кого не эвакуировали, и-стылно сказать - даже коммунисть из московских райкомов, и разразилась безудержная московская паника 16 октября, когда все уже считали столииу сданной. (А. И. Солженицын. На краях).

На праздник Яриль, в ярилкин день, совершались игры, угощения, пьянство, кулачные драки и, чего греха таить, невестились девчата напропалую. (И. Мартынов. Восстановление потенции в условиях демократии // «Столица», 1997.05.27).

Как с дедовщиной? - продолжает Калганов - Не скрою, бывают случаи. (Л. Данилкина. Аты-баты, шли солдаты (2012.12.01) // «Новгородские ведомости»).

Сопоставление сообщений с вводным признания и без него, ср.:

тут же стали бежать <..> - стылдо сказать - даже коммунисты $\mathbf{V S}$

тут же стали бежать < .. > даже коммунисть

чего греха таить, невестились девчата напропалую VS

невестились девчата напропалую.

диагностирует наличие в таких РА признания компонента 'солидарная ответственность. за действия, деятельность «соплеменников»', людей, с которыми говорящий связан узами родства, профессионально и социально. Признаваясь в такого рода проступках кого-л., говорящий сообщает, что берет на себя часть моральной ответственности за то, о чем он сообщает. При отсутствии вводного такие высказывания должны интерпретироваться как акты обвинения или осуждения. Наличие вводного признания снимает осуждение, переводя высказывание в статус «сетования» под воздействием, возможно, библейской заповеди «не суди и не судим будешь». 
3) Оценочные суждения говорящего (неличное участие говорящего, мнение, негативная / позитивная оценка). В косвенных РА такого рода также не встречаются вводные с компонентами сознаваться, каяться. Очень активно представлена единица положа руку на сердиее.

3.1.1. Негативная оценка чего- или кого-либо.

«Положса руку на сердце, - писал он, - мне всегда были не по душе ваши, Александр Яковлевич, намеки на духовную и умственную ущербность нашего, столь чуждого вашему нутру, народа». (В. Аксенов. Новый сладостный стиль).

По совести сказать, район и дом, где я живу, оставляют желать лучшего. (И. Павская. «Джоконда» Мценского уезда).

Так, представители КПРФ и их сводные братья из леворадикального крыла до сих пор используют примелькавшиеся и, чего греха таить, изрядно надоевшие лозунги-итампы типа “Правда за коммунистами!”. (А. Свешников. Не один в поле воин // «Богатей» (Саратов), 2003.11.13).

Вообще, поскольку гуманитарная наука в нашей ситуаџии обеспечивается государственным бюджетом, вопрос о ее статусе - это, стылно сказать, воnрос о деньгах. (М. Живов. Наука выживания и выживание науки)

3.1.2. Признание неважности чего-л., безразличия к чему-л. в реальности.

Да и, положа руку на сердце, не нужно это никому. Расшифрую или нет кому до этого есть дело? (М. Кучерская. Тетя Мотя).

Пусть понюхают пороху, да и какой, по совести сказать, в Москве порох... (В. Курицын. День независимости).

Но, надо признаться, картинки были довольно распльвчатьи и с ними мирились по принщипу “на безрыбье... “ (И. Лалаянц. Завтра, завтра... послезавтра!)

Сопоставление сообщений с вводным признания и без него, ср.:

По совести сказать, район и дом < .. > оставляют желать лучшего VS

Район и дом <... оставляют желать лучшего.

чего греха таить, изрядно надоевшие лозунги-итампь VS

изрядно надоевиие лозунги-итампьл.

Да и, положа руку на сердие, не нужно это никому. VS Да и не нужно это никому.

диагностирует наличие в высказывании без вводного компонента субъективную категоричность утверждения, которая может вызывать у собеседника несогласие и протест. Использование вводного оборота приводит к снятию категоричности и большей убедительностью: потаенному, вынужденно раскрываемому естественно быть истинным. 
3.1.3. Нечасто встречающаяся уступительно-позитивная оценка кого-л. выступает как вариация негативной оценки ввиду использования ее в уступительных конструкциях. Это до определенной степени риторический «реверанс», усиливающий воздействие через игровую вынужденность признания.

Масхадов потерял остатки престижа, который у него, надо признаться, был за пределами России. (А. Братерский. Газета «Известия»).

Cp.:

престижа, который у него, надо признаться, был VS

престижа, который у него был.

3.2. Парадоксальное, необщепринятое мнение о чем-л.

А я, грешныл делом, думаю, что и Льсенко на костёр пошёл бы ради своей ложной идеи. Он убеждён был, недаром обещуал быстрые успехи. В том была его сила (Д. Гранин. Зубр).

- Я, по правде говоря, вообще не понимаю, для чего человеку на вершине власти писать стихи, - сказал Олег, озадаченный непривычно восторженным тоном Тимура. (Е. Чижов. Перевод с подстрочника).

Как кажется, здесь вводные «самооусуждением» снижают градус категоричности и опасность возникновения полемики ввиду несогласия и протеста собеседника.

3.3. Похвала, комплимент, рекламирование кого- или чего-л. Данная типовая ситуация имеет положительную оценку, здесь также собраны косвенные РА, маскирующиеся под признания. Не используются вводные сознаваться, каяться, а зато в ироническо-игровом ключе активно используется вводное чего греха таumb.

Последнее время Стелла шьет «вегетарианскую», и весьма симпатичную, надо признаться, одежду под маркой Stella McCartney. (А. Карабаш. Чей туфля?)

По правде говоря, смотреть на прикольи и выходки дерзкого Тони Старкадаже интереснее, чем на Железного человека!!! Превосходное единение актера с ролью!! Роберт - молодец!!! (коллективный. Форум: Железный Человек, Iron Man (2008).

Надо признаться, будоражит, когда мощный автомобиль забывает про степенность и размеренность и начинает резвиться вместе с водителем. (С. Воскресенский. Эмоциональность интеллигента).

Иронически-игровая стратегия похвалы:

В Самаре, чего греха таить, пляжи не хуже, чем в Москве. (Н. Фохт. Запасная Москва) 
Чего греха таить, есть такие пенсионерь, которые сто очков вперед дадут любому молодому. (Т. Ильинкова. Зарплату надо зарабатывать)

Трудился Валентин Васильевич в Узбекистане и на Таймыре, в Таджикистане u, чего греха таить, в Чернобыле тоже трудился. Понятно, что без героизма в биографии Валентина Васильевича не обошлось. (А. Васильев. Фундаментman (1997) // «Столица»),

- Mbl здесь, чего греха таить, люди творческие и талантливые. Так пускай творчество братьев станет известно простым людям. (О. Демьянова. Творческий юбилей близнецов // «Столица», 1997.03.18)

В русской культуре комплимент часто предполагает неискренность, похвала - еще и возможную заинтересованность говорящего (За что же, не боясь гре$x a$, кукушка хвалит петуха?). Открытая похвала может вызвать подозрения. Одна из стратегий положительной оценки чего-л. — это как бы неохотная, вынужденная похвала, признание достоинств. Использование похвалы, одобрения в качестве вынужденного признания обладает убедительностью, снимает сомнения в искренности говорящего.

Cp.:

Стелла шьет весьма симпатичную, надо признаться, одежду VS Стелла шьет весьма симпатичную одежду.

В Самаре, чего греха таить, пляжи не хуже, чем в Москве VS В Самаре пляжи не хуже, чем в Москве

\section{Выводы}

Бытовые признания выходят за рамки смыслов, составляющих значение речевого глагола признаться и используются шире своего первоначального предназначения. Сообщения в форме признания добавляют к компоненту вынужденности уточнения в виде легкого раскаяния или сожаления - искреннего или игрового, что служит убедительности высказывания и увеличивает доверие между собеседниками. Видимо, поэтому в речи РА признания столь частотны и имеют такое количество вводных единиц.

Раскаянию и сожалению подлежат в признаниях как несерьезные или утратившие актуальность проступки, так и отступления от этических и этикетных эталонов поведения.

Сопоставляя сообщения с и без вводных признания, мы обнаружили неявные, возможно, национальные особенности речевого этикета. Но увереннее об этом можно говорить только при сопоставительном анализе на материале разных языковых культур. 


\title{
Литература
}

Апресян Ю.Д. Свойства прагматической информации. Прагматическая информация для толкового словаря // Избранные труды Т. 2. М. : Школа Языки русской культуры, 1995. С. 135-155.

Баранов А.Н., Кобозева И.М. Вводные слова в семантической структуре предложения // Системный анализ значимых единиц русского языка. Синтаксические структуры. Межвузовский сборник. Красноярск, 1984. С. 83-93.

Верещагин Е. М., Ратмайр Р., Ройтер Т. Речевые тактики “призыва к откровенности" // Вопросы языкознания, 1992. № 6. С. 82-93.

Виноградов В. В. О категории модальности и модальных словах в русском языке // Труды Ин-та русского языка АН СССР, М.-Л. : Изд-во АН СССР, т. 2, 1950. С. 38-89.

Гловинская М. Я. Семантика глаголов речи с точки зрения речевых актов.// Русский язык в его функционировании. Коммуникативно-прагматический аспект. М. : Наука, 1993. С. 158-217.

Падучева Е. В. Семантические исследования. Семантика времени и вида в русском языке. М. : Языки славянской культуры. 2011, 464 с.

Розина Р.И. Так называемый: семантика вводных метаязыковых оборотов // Материалы международной конференции Диалог 2009, вып. 8 (15). М., 2009. C. $426-432$.

Шаронов И. А. Зачем и в чем мы признаемся: анализ вводных слов со значением признания // “Взаимодействие языка и культуры в коммуникации и тексте”: сб. науч. ст. / III Международные филологические чтения им. проф. Р.Т. Гриб (1928-1995). Красноярск: Сибирский федеральный университет, 2012. Вып.3 (12). С. 101-106.

Шаронов И.А. Семантические и прагматические аспекты описания вводных слов и коммуникативов // Вестник Томского государственного университета. Филология. 2018. № 51. С. 58-68.

Leech G. N. Principles of Pragmatics. London : Longman, 1983.

Wierzbicka A. Rev. of: G. Leech, Principles of Pragmatics. L. 1983. Journal of the Australia Linguistic Sociaty, 1984, № 1

\author{
Igor A. Sharonov \\ Russian State University for Humanities \\ (Russia, Moscow). \\ Igor_sharonov@mail.ru
}

\section{INTRODUCTORY PHRASES AS MARKERS AND MODIFIERS OF SPEECH ACTS: EVERYDAY CONFESSIONS}

The article is devoted to pragmatic analysis informative statements, marked with introductory phrases of confession in smth. We compiled the data from Russian National Corpus and analyze statements with the twelve stereotypic introductory phrases. These 
language units are borrowed from the repentance lexicon: to confess, to repent, to admit; from the sincerity lexicon: not to hide, frankly, honestly, truth, conscience, sin; with the necessity: need, necessary, must. Speech acts of confession spread behind the frames of semantic components, that compile the meaning of the verb to confess. They are used in many situations different from its prototypical purpose. The speech acts of confession are used in three generalized situations: 1 . Statements about the speaker's actions (personal activity, fact in the past time, negative evaluation). 2. Statements about smb's actions (non-personal activity, fact in the past or in present time, negative/positive evaluation). 3. Value judgments (non-personal activity, opinion, negative/positive evaluation). The statistical analysis helps to find out fuzzy boundaries for some introductory phrases usage. The comparative analysis of statements with confession units and the same statements without these units revealed some ethical settings, overcome with the statements of confession, and perhaps national peculiarities of the speech etiquette.

Keywords: introductory phrases, pragmatics, subjective mood, speech acts, speech genre of confession.

\section{References}

Apresyan Yu.D. [Properties of pragmatic information. Pragmatic information for the explanatory dictionary] // Izbrannye trudy [Selected Works] v. 2. Moscow, Shkola Yazyki russkoi kul'tury Publ.1995, pp. 135-155.

Baranov A. N., Kobozeva I. M. [Introduction words in the semantic structure of the sentence // Sistemnyj analiz znachimyx edinic russkogo yazyka. Sintaksicheskie struktury. [System analysis of the significant units of the Russian language. Syntactic structures] Mezhvuzovskij sbornik. Krasnoyarsk, 1984, pp. 83-93. (In Russ.)

Vezhbickaya A. Metatekst v tekste [Metatext in text] // Novoe v zarubezhnoj lingvistike. [New in foreign linguistics] Moscow, 1978, Vyp. 8, pp. 402-421. (In Russ.)

Vezhbickaya A. Nabroski k russko-semanticheskomu slovaryu [Sketches to the Russian-semantic dictionary] // NTI, Ser. 2, № 12, 1968. (In Russ.)

Vereshhagin E. M., Ratmajr R., Rojter T. [Speech tactics "call for candor"] // Voprosy Yazykoznaniya. Moscow, 1992. № 6, pp. 82-93. (In Russ.)

Vinogradov V.V. O kategorii modalnosti i modalnyx slovax v russkom yazyke [On the category of modality and modal words in Russian] // Trudy in-ta russkogo yazyka AN SSSR. v. 2, Moscow — Leningrad, Izd-vo AN SSSR, 1950, pp. 38-89. (In Russ.)

Glovinskaya M. Ya. [The semantics of the verbs of speech in terms of speech acts] // Russkij yazyk $v$ ego funkcionirovanii. Kommunikativno-pragmaticheskij aspekt [Russian language in its functioning. Communicative and pragmatic aspect]. Moscow, Nauka Publ, 1993, pp. 158-217. (In Russ.)

Paducheva E. V. Semanticheskie issledovaniya semantika vremeni $i$ vida v russkom yazyke. [Semantic research. The semantics of time and aspect in Russian] Moskva. Yazyki slavyanskoj kultury Publ. 2011, 464 p.

Rozina R.I. Tak nazyvaemyi: semantika vvodnykh metayazykovykh oborotov [The so-called: semantics of introductory meta-language expressions]// Materialy 
mezhdunarodnoi konferencii Dialog 2009, Vyp. 8 (15). Moscow. 2009, pp. 426-432. (In Russ.)

Sharonov I. A. [Why and what we admit: analysis of introductory words with the meaning of recognition] // "Vzaimodejstvie yazyka i kultury v kommunikacii i tekste": Sb. nauch. st. / III mezhdunarodnye filologicheskie chteniya im. prof. R. T. Grib (19281995). [The interaction of language and culture in communication and text / Digest of articles. III International philological reading in honour of prof. R. T. Grib (1928-1995)], Krasnoyarsk: Sibirskii federalnyi universitet, 2012. Vyp.3 (12), pp. 101-106. (In Russ.)

Sharonov I.A. [Semantic and pragmatic aspects of the description of introductory words and communication] // Vestnik Tomskogo gosudarstvennogo universiteta. Filologiya. 2018. № 51, pp. 58-68. (In Russ.) 